\title{
PERBANDINGAN MANAJEMEN KINERJA KARYAWAN DIFABEL PADA USAHA KECIL MENENGAH X DAN USAHA KECIL MENENGAH Y
}

\author{
Agnes Thedora ${ }^{1}$, Rostiana ${ }^{2}$, dan Daniel Lie ${ }^{3}$ \\ ${ }^{1}$ Fakultas Psikologi Universitas Tarumanagara, Jakarta \\ Email: nes.thedora@gmail.com \\ ${ }^{2}$ Fakultas Psikologi Universitas Tarumanagara, Jakarta \\ Email: rostiana@fpsi.untar.ac.id \\ ${ }^{3}$ Fakultas Psikologi Universitas Tarumanagara, Jakarta \\ Email: danielsugiantolie@gmailcom
}

\begin{abstract}
ABSTRAK
Latar belakang penelitian ini adalah permasalahan yang dihadapi oleh UKM X dan UKM Y yang mempekerjakan karyawan difabel. UKM X memiliki tingkat turnover yang tinggi dan tingkat produktivitas yang rendah. Sebaliknya UKM Y memiliki tingkat turnover yang rendah dan tingkat produktivitas yang tinggi. Diasumsikan kedua UKM memiliki masalah pada praktik manajemen kinerja selama tiga tahun terakhir. Berdasarkan permasalahan tersebut, tujuan dari penelitian ini adalah untuk melihat bagaimana praktik manajemen kinerja dijalankan di UKM yang mempekerjakan difabel. Subjek dari penelitian ini adalah dua UKM yang mempekerjakan difabel. Pengambilan data menggunakan metode penelitian kualitatif, yakni dengan menggunakan teknik wawancara mendalam pada subjek penelitian. Manajemen performa didefinisikan sebagai proses sistematis untuk meningkatkan kinerja organisasi dengan mengembangkan kinerja individual dan tim. Hasil dari penelitian ini menunjukkan bahwa UKM Y yang menjalankan manajemen kinerja sesuai dengan kaidah International Labour Organization (ILO) dan konsep Armstrong dan Baron dengan memperhatikan aspek-aspek sepeti manajemen rekrutmen, orientasi, kinerja, dan penyesuaian kesetaraan dalam mengelola difabel memiliki tingkat turnover yang rendah dan tingkat produktivitas yang lebih baik dibandingkan dengan UKM X yang belum sepenuhnya menjalankan manajemen kinerja sesuai dengan kaidah ILO dan konsep Armstrong Baron.
\end{abstract}

Kata Kunci: manajemen kinerja, karyawan difabel, usaha kecil menengah

\section{PENDAHULUAN}

Huselid (1995) mengatakan bahwa salah satu aspek yang penting dalam mengelola keberagaman SDM dalam organisasi adalah manajemen kinerja. Mendukung pernyataan Huselid (1995), Armstrong (dalam Wibowo, 2007) juga mengatakan bahwa manajemen kinerja merupakan salah satu aspek dari manajemen SDM yang mempengaruhi tercapainya tujuan sebuah organisasi, termasuk organisasi yang mempekerjakan difabel sebagai karyawan.

Kehadiran kaum difabel sebagai bagian dari kehidupan sosial kemasyarakatan telah menjadi sesuatu yang faktual dan signifikan. Dari segi jumlah, mengacu kepada hasil Survei Sosial Ekonomi Nasional yang dilaksanakan Badan Pusat Statistik (2012) jumlah penyandang disabilitas di Indonesia sebanyak 6.008.661 orang. Sebagaimana terpapar dalam Convention on the Right of Person with Disabilities tahun 2007 di New York, Amerika Serikat, negara-negara di dunia telah menyepakati bahwa difabel adalah orang yang memiliki keterbatasan fisik, mental, intelektual, atau sensorik dalam jangka waktu lama yang dalam berinteraksi dengan lingkungan dapat menemui hambatan yang menyulitkan untuk berpartisipasi penuh dan efektif.

Meskipun perlindungan dari pemerintah nampak adekuat dengan adanya ragam aturan-aturan seperti: memastikan bahwa penyandang cacat memiliki kesempatan yang sama di tempat kerja, meningkatkan peluang kerja bagi difabel, mengusahakan adanya tempat kerja yang nyaman, namun kenyataan bahwa individu difabel sebagai karyawan di perusahaan masih terdiskriminasi 
baik dari segi performa maupun sosial, membuat mereka merasa tidak diterima karena kapasitas mereka yang terbatas.

Kehadiran UKM ini merupakan salah satu solusi penting dan bernilai tinggi bagi para difabel. UKM membuka peluang bagi difabel tidak hanya untuk bekerja dan membangun potensi kemandirian finansial, tetapi juga memaknai diri mereka sendiri melalui self worth yang positif. Memiliki rutinitas kerja yang bermakna, menjadi bagian terintegrasi yang diakui dari suatu organisasi, peluang bersosialisasi dengan sesama difabel ataupun pekerja lain yang tidak menyandang disabilitas merupakan faktor-faktor yang berkontribusi signifikan terhadap keberdayaan difabel.

Di Yogyakarta, terdapat dua Usaha Kecil Menengah (UKM) yang membuka lapangan pekerjaan bagi difabel yaitu UKM X dan UKM Y. Kedua UKM ini seluruh karyawannya adalah karyawan difabel. UKM X didirikan pada bulan Febuari tahun 2014 merupakan salah satu UKM yang menjual eskrim yang memiliki kurang lebih 25 karyawan difabel. Sedangkan UKM Y didirikan pada bulan Oktober tahun 2013 merupakan salah satu UKM yang bergerak di bidang kerajinan tangan seperti tas kain dan rumah boneka yang memiliki 34 karyawan difabel.

Antara UKM X dan UKM Y terjadi perbedaan gambaran kinerja pada karyawan. Berikut ini adalah nilai persentasi (\%) turnover karyawan UKM X dan UKM Y tahun 2014 sampai 2016, yang diinformasikan berdasarkan Tabel 1 berikut:

Tabel 1. Tabel Tingkat Turnover periode 2014-2016 di UKM X dan UKM Y

\begin{tabular}{cccccccccc}
\hline Turn Over & \multicolumn{3}{c}{2014} & \multicolumn{3}{c}{2015} & \multicolumn{3}{c}{2016} \\
& Jumlah & Out & $\%$ & Jumlah & Out & $\%$ & Jumlah & Out & $\%$ \\
\hline UKM X & 38 & 3 & 7.9 & 35 & 4 & 11.4 & 31 & 6 & 19.3 \\
UKM Y & 37 & 3 & 8 & 34 & 2 & 6 & 35 & 1 & 3 \\
\hline
\end{tabular}

Berdasarkan Tabel 1, dapat disimpulkan bahwa sejak 2014 sampai dengan Desember 2016, angka turnover pada UKM X mengalami peningkatkan yang cukup signifikan jika dibandingan dengan UKM Y. Walaupun persentase turnover pada UKM X belum mencapai 50\%, angka turnover yang meningkat di UKM X menjadi pertanyaan karena tidak banyak lapangan pekerjaan yang mempekerjakan difabel, namun ketika mendapatkan pekerjaan persentase UKM $\mathrm{X}$ yang mengundurkan diri meningkat dengan berbagai alasan seperti beban kerja tidak sesuai dengan keterbatasan fisik dan kemampuan komunikasi bersifat instruktif sehingga karyawan merasa tidak diperlakukan dengan baik. Padahal, dengan adanya kesempatan bagi difabel untuk bekerja, UKM X seharusnya mampu mengelola sumber daya manusianya khususnya difabel dengan baik sehingga angka turnover rendah.

Sulistyawati dan Indrayani (2012) beserta Park dan Shaw (2013), menjelaskan bahwa tingkat turnover yang tinggi dapat menyebabkan produktivitas menurun. Hal ini juga terjadi pada UKM $\mathrm{X}$ dan UKM Y. Berikut ini adalah nilai persentase (\%) produktivitas karyawan UKM tahun 2014-2016, yang diinformasikan berdasarkan Tabel 2 berikut: 
Tabel 2. Tabel Tingkat Produktivitas Karyawan UKM X periode 2014-2016

\begin{tabular}{llllllllll}
\hline $\begin{array}{l}\text { Produkt } \\
\text { ivitas }\end{array}$ & 2014 & \multicolumn{9}{c}{2015} & & 2016 & \\
\cline { 2 - 8 } & Pesanan & $\begin{array}{l}\text { Target } \\
\text { /Tahu } \\
\mathrm{n}\end{array}$ & $\%$ & Pesanan & $\begin{array}{l}\text { Target } \\
\text { /Tahu } \\
\mathrm{n}\end{array}$ & $\%$ & Pesanan & $\begin{array}{l}\text { Target/Tahu } \\
\mathrm{n}\end{array}$ & $\%$ \\
\hline UKM \\
$\mathrm{X}$
\end{tabular}

Berdasarkan Tabel 2, dapat disimpulkan bahwa selama tiga tahun menjalankan bisnisnya, UKM $\mathrm{X}$ belum dapat memenuhi target yang ditentukan setiap tahunnya yaitu 2000 unit barang. Sebaliknya, meskipun UKM Y belum mencapai target yang ditetapkan namun terjadi peningkatan pemenuhan target yang terjadi setiap tahunnya. Tabel 3 menunjukkan tingkat produktivitas karyawan UKM Y periode 2014-2016.

Tabel 3. Tabel Tingkat Produktivitas Karyawan UKM Y periode 2014-2016

\begin{tabular}{llllllllll}
\hline $\begin{array}{l}\text { Produkti } \\
\text { vitas }\end{array}$ & 2014 & \multicolumn{1}{c}{2015} & \multicolumn{7}{c}{2016} \\
\cline { 2 - 9 } & $\begin{array}{l}\text { Pesan } \\
\text { an }\end{array}$ & $\begin{array}{l}\text { Target/ } \\
\text { Tahun }\end{array}$ & $\%$ & Pesanan & $\begin{array}{l}\text { Target/ } \\
\text { Tahun }\end{array}$ & $\%$ & Pesanan & Target/Tahun & $\%$ \\
\hline UKM Y & 780 & 1000 & 78 & 832 & 1000 & $\begin{array}{l}83 . \\
2\end{array}$ & 832 & 1000 & 83.2 \\
\hline
\end{tabular}

Berdasarkan data yang turnover dan produktivitas pada Tabel 1, 2, dan 3 secara konsisten terlihat bahwa pada UKM X tingkat turnover setiap tahun meningkat dan produktivitas setiap tahun menurun. Sebaliknya pada UKM Y, tingkat produktivitas meningkat dan tingkat turnover menurun. Huselid (1995) mengatakan bahwa, tingkat produktivitas dan turnover dipengaruhi oleh bagaimana sebuah unit bisnis melakukan manajemen kinerja. Pengelola UKM Y juga mengatakan bahwa banyak konsumen yang puas dengan kualitas barang yang dihasilkan oleh karyawan UKM Y. Hal ini ditandai dengan pemesanan berulang dari konsumen yang sama, pemberian gaji yang tidak pernah terlambat, dan meningkatnya pendapatan setiap tahunnya.

Menarik untuk diperhatikan bahwa apakah benar manajemen kinerja menjadi salah satu faktor yang mempengaruhi perkembangan unit bisnis, mengingat unit bisnis dalam penelitian ini mempekerjakan seluruh karyawannya adalah difabel.

Reputasi UKM X dalam mengelola sumber daya dan kinerja karyawan difabelnya menjadi pertanyaan. Apa yang menyebabkan UKM X dan UKM Y memiliki tingkat turnover dan produktifitas yang berbeda. Faktor-faktor apa saja yang menyebabkan terjadinya perbedaan tersebut dan seperti apa manajemen kinerja yang dilakukan oleh UKM X dan UKM Y sehingga memiliki dampak terhadap kemajuan bisnisnya. Terkait hal ini, apakah kesiapan sebuah unit bisnis dalam mengelola karyawan difabel sesuai dengan kaidah International Labour Organization (ILO) memiliki signifikansi terhadap kemajuan bisnis dan performa karyawan difabel.

Dari sudut pandang organisasi, sebagai suatu organisasi yang hidup dan berkembang, UKM pun dituntut untuk melakukan berbagai penyesuaian-penyesuaian yang dibutuhkan, memastikan bahwa integrasi karyawan difabel ke dalam tata laksana SDM tetap mengakomodir esensi 
efektivitas dan efisiensi pencapaian tujuan organisasi dan tetap menjaga keseimbangan dan optimalisasi kinerja melalui manajemen kinerja. Huselid (1995) mengatakan bahwa salah satu praktik pengelolaan SDM yang mempengaruhi perkembangan bisnis UKM adalah manajemen kinerja.

ILO mengeluarkan kaidah-kaidah yang harus diperhatikan oleh perusahaan dalam mengelola karyawan difabel. Satu hal yang menarik untuk diperhatikan adalah apakah kaidah ILO dalam mengelola karyawan difabel menjadi faktor utama yang menentukan apakah UKM dapat berfungsi optimal dalam pencapaian tujuan-tujuannya dan memastikan eksistensi sebuah unit bisnis dapat berkembang. Selain pencapaian tujuan sebuah unit bisnis, apakah kaidah ILO terkait manajemen kinerja jika diterapkan akan meningkatkan kemampuan sebuah unit bisnis dalam persaingan dan ekosistem yang lebih besar.

Dari sisi yang lain, efektivitas kinerja merupakan refleksi langsung dari kualitas sumber daya manusia yang dimilikinya, komponen vital yang menentukan apakah UKM sudah memiliki perspektif manajemen dalam mengelola sumber daya manusianya sebagai aset, bukan lagi perspektif eksploitatif yang sudah tidak lagi relevan.

Konsep manajemen kinerja ditinjau dari kaidah yang dikeluarkan oleh ILO (2016), prinsipprinsip pengelolaan karyawan difabel harus memperhatikan aspek-aspek seperti kesetaraan dalam proses rekrutmen dan kesetaraan di tempat kerja, keterampilan dan kualitas kerja, serta kontribusi bagi unit bisnis. Dari permasalahan diatas, peneliti ingin mengeksplorasi, apakah betul manajemen kinerja menjadi salah satu faktor penentu keberhasilan dari sebuah UKM yang seluruh karyawannya adalah difabel.

Berdasarkan aspek-aspek tersebut, secara spesifik ditinjau dari perbedaan output kedua UKM tersebut, maka ingin diketahui bagaimana kedua UKM melakukan manajemen kinerja karyawan difabel yang mengandung aspek-aspek seperti rekrutmen dan seleksi karyawan difabel, orientasi karyawan difabel, pelatihan dan pengembangan karyawan difabel, monitoring kinerja dan pengelolaan kinerja karyawan difabel. Jadi penelitian ini betujuan untuk mengidentifikasi bagaimana praktik manajemen kinerjadilakukan oleh UKM serta menggambarkan pengaruhnya terhadap keberhasilan bisnis dan seberapa jauh UKM X dan UKM Y telah menerapkan manajemen kinerja untuk kesejahteraan difabel dalam konteks kerja.

Berdasarkan gambaran permasalahan yang terjadi di UKM X dan UKM Y, yaitu perbedaan tingkat turnover yang meningkat di UKM X dan tingkat turnover yang menurun di UKM Y serta kegagalan pencapaian target pada UKM X dan pencapaian target yang meningkat di UKM Y, peneliti ingin mengetahui bagaimana implementasi manajemen kinerja di UKM X dan UKM Y berdasarkan kaidah ILO (2015) dan konsep teoretis Armstrong dan Baron (2005). Penelitian ini dapat menambah perbendaharaan pengetahuan mengenai implementasi manajemen kinerja di suatu UKM yang mempekerjakan difabel, agar berhasil menjaga turnover berada pada tingkat yang rendah.

ILO mengungkapkan bahwa manajemen karyawan difabel mengandung aspek-aspek seperti manajemen rekrutmen, orientasi, promosi dan penyesuaian kesetaraan. Terkait tata kelola kinerja difabel, secara teoretis Armstrong dan Baron mengungkapkan bahwa manajemen kinerja terdiri dari aspek-aspek: performance contract, rencana kinerja dan pengembangan, monitoring, dan penilaian kinerja. 
Berdasarkan uraian tersebut, maka kerangka berpikir penelitian akan digambarkan dalam gambar 1 .

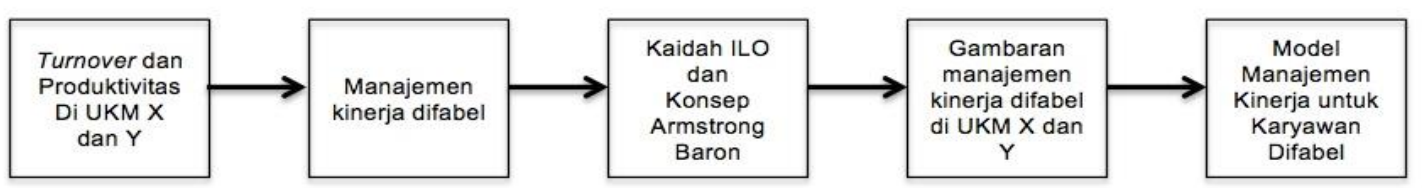

Gambar 1. Gambaran Kerangka Berpikir Penelitian

Dalam penelitian ini, peneliti akan memaparkan perbandingan model manajemen kinerja dari UKM X dan UKM Y bagi kaum difabel yang dapat mengakomodir pendekatan konseptual teoretis serta aturan-aturan yang ditentukan oleh ILO, dengan menggabungkan kedua konsep tersebut. Secara ringkas dapat dilihat pada Tabel 4.

Tabel 4. Tabel Hasil Penelitian

\begin{tabular}{|c|c|c|c|c|}
\hline \multicolumn{2}{|l|}{$\begin{array}{l}\text { Aspek Manajemen } \\
\text { Kinerja yang Diukur }\end{array}$} & UKM X & UKM Y & Kesimpulan \\
\hline 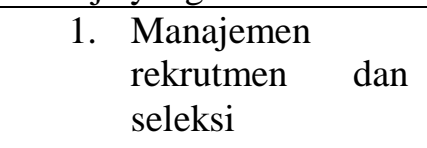 & $\begin{array}{ll}- & \text { Rekrutmen } \\
- & \text { Seleksi }\end{array}$ & & & \\
\hline $\begin{array}{l}\text { 2. } \begin{array}{l}\text { Manajemen } \\
\text { orientasi }\end{array} \\
\text { oris }\end{array}$ & & & & \\
\hline $\begin{array}{l}\text { 3. Manajemen } \\
\text { kinerja }\end{array}$ & $\begin{array}{ll}\text { - } & \text { Performance contract dan } \\
& \text { pengembangan } \\
\text { - } & \text { Rencana kinerja dan } \\
& \text { pengembangan } \\
\text { - } & \text { Monitoring dan umpan balik } \\
\text { - } & \text { Penilaian kinerja } \\
\end{array}$ & & & \\
\hline $\begin{array}{l}\text { 4. Manajemen } \\
\text { Promosi }\end{array}$ & $\begin{array}{ll}- & \text { Pengembangan Karir } \\
- & \text { Pelatihan dan kursus, pedoman } \\
\text { bekerja }\end{array}$ & & & \\
\hline $\begin{array}{l}\text { 5. Manajemen } \\
\text { penyesuaian } \\
\text { kesetaraan }\end{array}$ & $\begin{array}{ll}- & \text { Aksesibilitas } \\
- & \text { Penyesuaian lingkungan kerja }\end{array}$ & & & \\
\hline
\end{tabular}

\section{METODE PENELITIAN}

\section{Partisipan}

Partisipan penelitian ini adalah dua UKM di Yogyakarta yang mempekerjakan difabel yaitu UKM X dan UKM Y. UKM X bergerak di bidang makanan dan minuman khususnya es krim. UKM X sudah berdiri sejak Febuari 2014 dengan 25 karyawan difabel. Difabel di UKM X terdiri dari delapan karyawan tuna rungu dan tuna wicara, 17 karyawan tuna daksa. UKM Y bergerak di bidang kerajinan tangan khususnya rumah boneka dan tas kain. UKM Y sudah 
berdiri sejak Oktober dengan 34 karyawan difabel. Difabel di UKM Y terdiri dari delapan karyawan tuna rungu dan tuna wicara, 26 karyawan tuna daksa.

\section{Desain Penelitian}

Desain penelitian yang digunakan dalam penelitian ini adalah non-experimental dengan menggunakan metode kualitatif yang menggunakan teknik wawancara dan observasi kepada subjek penelitian. Wawancara dalam metode kualitatif bertujuan untuk melihat gambaran yang lebih mendalam mengenai proses yang terjadi dalam praktik kinerja di kedua UKM.

\section{Prosedur Penelitian}

Setelah menentukan masalah penelitian, teori, dan metode penelitian, dan panduan wawancara, langkah selanjutnya yang dilakukan peneliti adalah menghubungi subjek dan menanyakan kesediaan mereka untuk menjadi subjek dalam penelitian ini sehingga akhirnya dapat membuat kesepakatan mengenai waktu pelaksanaan dan tempat wawancara. Setelah semua data berupa rekaman wawancara diperoleh, peneliti mulai mengolah data untuk merumuskan hasil penelitian. Hasil wawancara diolah dengan membuat verbatim dan laporan hasil wawancara yang berisi data subjek, hasil observasi, dan tabel verbatim wawancara. Setelah itu, peneliti membuat tabel mapping dan coding guna memperoleh tema-tema hasil wawancara. Data yang telah diolah tersebut digunakan sebagai dasar perumusan hasil penelitian, pembahasan, dan simpulan.

\section{Alat Penelitian}

Data penelitian dikumpulkan dengan menggunakan panduan wawancara berdasarkan konsep teoretis manajemen kinerja Armstrong dan Baron yang terdiri dari performance contract, rencana kinerja dan pengembangan, monitoring dan umpan balik, dan penilaian kinerja. Beberapa contoh pertanyaan yang diajukan adalah (1) 'Bagaimana cara bapak/ibu mengkomunikasikan tugas dan tanggungjawab mereka sebagai karyawan?' (2) 'Bagaimana strategi anda dalam mengelola karyawan yang berprestasi dan kurang berprestasi?' (3) 'Apa saja yang menjadi poin-poin penting ketika evaluasi karyawan?' (4) 'Bagaimana anda mengevaluasi kinerja dan perkembangan dari para karyawan anda?'. Selanjutnya panduan wawancara berdasarkan manajemen kinerja menurut kaidah ILO yang terdiri dari manajemen rekrutmen dan seleksi, manajemen orientasi, manajemen promosi, manajemen penyesuaian kesetaraan. Contoh pertanyaan yang diajukan adalah (1) 'Persiapan apa saja yang dilakukan sebelum merekrut karyawan difabel? Untuk mengakomodir mereka.' (2) 'Bagaimana orientasi karyawan dijalankan? Apa saja konten yang diinformasikan kepada karyawan ketika masa orientasi? Mengapa itu penting' (3) 'Posisi apa saja yang ditempati oleh karyawan difabel? Bisa meningkat?' (4) 'Penyesuaian apa yang dilakukan untuk mengakomodir mereka bekerja dan produktif?'.

\section{HASIL DAN PEMBAHASAN}

Ditinjau dari kerangka berpikir, dimensi manajemen kinerja yang ingin dilihat adalah manajemen rekrutmen dan seleksi, manajemen orientasi, manajemen kinerja, manajemen promosi, dan manajemen penyesuaian kesetaraan. Tabel 5 menunjukkan gambaran manajemen kinerja di UKM X dan Y. 
Tabel 5.Tabel Gambaran Manajemen Kinerja di UKM X dan Y

\begin{tabular}{|c|c|c|c|}
\hline Aspek & $\begin{array}{c}\text { Manajemen Kinerja } \\
\text { Difabel }\end{array}$ & UKM X & UKM Y \\
\hline \multirow{2}{*}{$\begin{array}{l}\text { Manajemen } \\
\text { rekrutmen } \\
\text { dan seleksi }\end{array}$} & Rekrutmen & Sesuai dengan kaidah ILO & Sesuai dengan kaidah ILO \\
\hline & Seleksi & Tidak sesuai dengan kaidah ILO & Sesuai dengan kaidah ILO \\
\hline \multirow{2}{*}{$\begin{array}{l}\text { Manajemen } \\
\text { Orientasi }\end{array}$} & Orientasi & Sesuai dengan kaidah ILO & Sesuai dengan kaidah ILO \\
\hline & Percobaan Kerja & Tidak sesuai dengan kaidah ILO & Sesuai dengan kaidah ILO \\
\hline \multirow{7}{*}{$\begin{array}{l}\text { Manajemen } \\
\text { Kinerja }\end{array}$} & Performance & Tidak sesuai dengan konsep & Sesuai dengan konsep \\
\hline & Contract & Armstrong dan Baron & Armstrong dan Baron \\
\hline & Rencana Kinerja & $\begin{array}{l}\text { Tidak sesuai dengan konsep } \\
\text { Armstrong dan Baron }\end{array}$ & $\begin{array}{l}\text { Sesuai dengan konsep } \\
\text { Armstrong dan Baron }\end{array}$ \\
\hline & Monitoring dan & Sesuai dengan konsep & Sesuai dengan konsep \\
\hline & Umpan Balik & Armstrong dan Baron & Armstrong dan Baron \\
\hline & Penilaian Kinerja & Tidak sesuai dengan konsep & Sesuai dengan konsep \\
\hline & & Armstrong dan Baron & Armstrong dan Baron \\
\hline \multirow[t]{2}{*}{$\begin{array}{l}\text { Manajemen } \\
\text { Promosi }\end{array}$} & $\begin{array}{l}\text { Pengembangan } \\
\text { Karir }\end{array}$ & Tidak sesuai dengan kaidah ILO & Tidak sesuai dengan kaidah ILO \\
\hline & $\begin{array}{c}\text { Pengembangan } \\
\text { Keterampilan }\end{array}$ & Tidak sesuai dengan kaidah ILO & Sesuai dengan kaidah ILO \\
\hline \multirow{2}{*}{$\begin{array}{l}\text { Manajemen } \\
\text { Penyesuaian } \\
\text { Kesetaraan }\end{array}$} & Aksesibilitas & Tidak sesuai dengan kaidah ILO & Sesuai dengan kaidah ILO \\
\hline & $\begin{array}{c}\text { Penyesuaian } \\
\text { Lingkungan Kerja }\end{array}$ & Tidak sesuai dengan kaidah ILO & Sesuai dengan kaidah ILO \\
\hline
\end{tabular}

Berdasarkan Tabel 6 dapat disimpulkan bahwa UKM X hanya melakukan manajemen kinerja sesuai dengan kaidah ILO dan konsep Armstrong Baron pada area manajemen rekrutmen, manajemen orientasi, dan monitoring karyawan. Sedangkan UKM Y sudah melakukan manajemen kinerja pada hampir seluruh area kecuali manajemen promosi.

\section{KESIMPULAN DAN SARAN}

\section{KESIMPULAN}

Penelitian yang dilakukan terhadap dua UKM untuk melihat bagaimana manajemen kinerja difabel yang dilakukan di UKM X dan UKM Y dapat disimpulkan bahwa salah satu faktor yang mempengaruhi tingkat turnover karyawan dan produktivitas sebuah organisasi yang mempekerjakan difabel dalam mencapai target adalah praktik manajemen kinerja. Karyawan difabel juga menjadi aset perusahaan yang harus dikelola sesuai dengan manajemen kinerja yang cocok untuk mereka. Berdasarkan hasil penelitian ini, manajemen kinerja yang dapat diterapkan untuk mengelola karyawan difabel adalah dengan memperhatikan aspek-aspek seperti penyesuaian tugas sesuai dengan kondisi fisik karyawan difabel. Selain itu, untuk mendukung tugas karyawan difabel, perusahaan perlu menyesuaikan beberapa fasilitas seperti alat-alat kerja dan ruang kerja karyawan difabel 


\section{SARAN}

Dalam penelitian selanjutnya penting untuk mempertimbangkan gaya kepemimpinan khas Indonesia yang dapat berpengaruh terhadap komponen-komponen seperti trust dan tata kelola relasi interpersonal dalam perusahaan dimana kaum difabel menjadi pekerja inklusi. Hal ini berguna untuk mengeksplorasi paradigma kultural dalam kepemimpinan situasional dan menjelaskan faktor apa yang paling dipengaruhi oleh warna kepemimpinan tertentu.

Selain itu dibutuhkan pengembangan grounded theory yang secara spesifik membahas perusahaan atau organisasi kerja yang mempekerjakan difabel sebagai acuan bagi perusahaan untuk menerapkan manajemen kinerja bagi karyawan difabel. Usaha mengembangkan teori ini diharapkan mencakup kaidah yang ditetapkan ILO supaya sejalan agar tidak ada kesenjangan antara aplikasi profesional dengan kaidah ILO.

Mengembangkan model manajemen kinerja khusus untuk difabel sebagai acuan bagi perusahaan dalam mengelola karyawan difabel. Hal ini diharapkan berguna bagi karyawan difabel sebagai bentuk umpan balik yang adil atas kinerjanya di tempat kerja.

\section{Saran yang Berkaitan dengan Manfaat Praktis}

Saran yang dapat diberikan kepada UKM X adalah dengan melihat permasalahan yang terjadi, perusahaan dapat mencoba kembali sistem manajemen kinerja yang lebih sistematis. Misalnya, pada area rekrutmen dan seleksi dengan meningkatkan pemahaman pemilik UKM $\mathrm{X}$ akan kompetensi-kompetensi yang harus dimiliki oleh karyawan dalam membuat es krim dalam merekrut karyawan difabel. Hal ini berguna untuk mencegah kesalahan dalam proses produksi seperti kebersihan produk yang dapat berdampak buruk bagi perspektif konsumen terhadap kompetensi karyawan difabel. Selain itu, mengadakan masa orientasi minimal 2 bulan agar pemilik dan calon karyawan lebih terpapar pada area tugas dan pengembangan keterampilan. Selain itu, pada area promosi jabatan, pemilik UKM X diharapkan untuk berdiskusi dengan karyawan sebelum memberikan beban kerja kepada karyawan. Pada area manajemen kinerja, diharapkan agar pemilik UKM X dapat menetapkan standar kerja untuk setiap karyawan dan mengkomunikasikan setiap standar kerja kepada karyawan sehingga karyawan memiliki perspektif yang utuh akan tugas dan tanggung jawabnya.

Selain itu pemilik UKM X diharapkan melakukan beberapa penyesuaian di area-area seperti peralatan yang digunakan untuk bekerja. Hal ini diharapkan agar karyawan difabel dapat bekerja dengan nyaman dan dapat menyelesaikan tugas-tugasnya dengan baik sehingga dapat meningkatkan self-esteem karyawan difabel. Selain itu, UKM X diharapkan melakukan penyesuaian padalingkungan kerja seperti toilet dan tangga. Dengan jalan tersebut, diharapkan pekerjaan akan lebih mudah dijalankan dan kesejahteraan karyawan meningkat sehingga dapat menyelesaikan tugas dan tanggung jawab dengan baik. Untuk pemilik UKM X diharapkan dapat belajar lebih banyak dalam menghargai pekerjaan karyawan difabel dan meningkatkan kepedulian terhadap kesejahteraan karyawan difabel dengan melakukan komunikasi personal sebagai bentuk dukungan terhadap karyawan difabel.

Saran untuk kaum difabel diharapkan dapat lebih memperhatikan informasi-informasi terkait LSM difabel sebagai akses untuk memeroleh pekerjaan. Selain itu, diharapkan dapat mengembangkan wawasan terkait regulasi-regulasi pemerintah yang melindungi difabel untuk membangun pemahaman terkait hak dan peluang difabel yang didukung pemerintah. 
Bagi para difabel yang berada di usia produktif, penting untuk bekerja secara profesional baik melalui wirausaha maupun dengan menjadi bagian dari organisasi tertentu. Hal ini tidak hanya membantu terbangunnya kemandirian finansial tetapi juga memberi dampak positif secara psikologis sebagai faktor yang membangun self esteem difabel. Dengan demikian mereka berpotensi menjadi individu yang dapat berfungsi secara optimal memenuhi tugas perkembangannya.

\section{Ucapan Terima Kasih}

Penulis mengucapkan terima kasih kepada Program Studi Magister Psikologi Universitas Tarumanagara yang telah memfasilitasi penelitian ini. Selain itu, terima kasih juga kepada subjek F, SR, karyawan UKM X, dan karyawan UKM Y yang telah bersedia untuk memberikan ijin untuk melakukan penelitian. Terlebih lagi peneliti berterima kasih kepada seluruh lembaga swadaya masyarakat difabel dan ILO atas perhatiannya kepada teman-teman difabel dalam memperjuangkan kesetaraan mereka sebagai individu, terutama di lingkungan kerja.

\section{REFERENSI}

Afung, S. R., Irvianti, L. S. D. (2014). Pengaruh praktek MSDM terhadap retensi karyawan dengan kepuasan kerja karyawan sebagai variabel mediasi pada sentra prima sarana. Kebon Jeruk: Binus University.

Armstrong, M., \& Baron, A. (Ed.1). (2005). Performance management. London: Institute of Personnel and Development

Badan Pusat Statistik. (2017). Survei sosial ekonomi nasional. Diakses dari www.bps.go.id.

Badan Pusat Statistik. (2017). Usaha mikro kecil. Diakses dari https://www.bps.go.id/Subjek/view/id/35\#subjekViewTab2

Butler, S.E., Crudden, A., Sansing, W.K. \& LeJeune, B.J. (2002). Employment Barriers: Access to Assistive Technology and Research Needs. Journal of Visual Impairment \& Blindness, 96(9), 664.

Darmaji, L. T. W., Atikasari, N., Saputra, M. D., \& Yunarti, D. A. (2013). Pendekatan situasional: Blanchard, Fiedler, path goal, dan substitusi (Mata kuliah kepemimpinan). Diakses dari: http://ymayowan.lecture.ub.ac.id/files/2012/01/

Ekwoaba, J. O., Ikieje, U. U., \& Ufoma, N. (2015). The impact of recruitment and selection criteria on organizational performance. Global Journal of Human Resource Management, $3(2), 22-33$.

Gartrell A. (2010). 'A frog in a well': the exclusion of disabled people from work in Cambodia. Disability \& Society, 25(3), 289-301. doi: Org/10. 1080/09687591003701207.

Huselid, M. (1995). The impact of human resource management practice on turnover, productivity, and corporate financial performance. Academy of Journal Management, 38(3), 635-872.

ILO. (2015). Pedoman ILO tentang: Pengelolaan penyandang disabilitas di tempat kerja. Jakarta: Organisasi Perburuhan Internasional

Kementrian Koperasi dan Usaha Kecil dan Menengah (Kemenkop UKM), diakses dari www.depkop.go.id/. Diakses pada tanggal 5 Oktober 2013 pada jam 21.05 WIB.

Kementerian Keuangan Republik Indonesia (2015). Kebijakan fiskal dan peningkatan peran ekonomi UMKM. Diakses dari https://www.kemenkeu.go.id/Artikel/kebijakan-fiskal-danpeningkatan-peran-ekonomi-umkm

Mamoria, C. B. (1997). Personnel management. Bombay: Himalaya Publishing House 
Hafeez, U. (2015). Effects of training on employee performance: Evidence from pharmaceutical companies in Karachi, Pakistan. Faculty of Business Administration, 6(1), 49-64. doi: 10. 5296/bms.v6il.7804

Park, T. Y., \& Shaw, J. D. (2013). Turnover rates and organizational performance: A Meta Analysis. Journal of Applied Psychology, 98, 268-309. doi: 10. 1037/a0030723.98.2.268

Presiden Republik Indonesia. (2016). Undang-undang republik indonesia nomor 8 tentang penyandang disabilitas. Diakses dari http://www.kemendagri.go.id/media/documents/2016/05/11/u/u/uu_nomor_8_tahun_201 6.pdf

Putzier, J., \& Baker, D. (2011). A complete guide to attracting, retaining \& motivating high performance employees. United States of America: Amacom (American Management Association).

Roberts, S., Heaver, C., Hill, K., \& Rennison, J. (2004). Disability in the workplace: Employers' and service providers' responses to the disability discrimination act in 2003 and preparation for 2004 changes. London: Department of Work and Pensions Research Summary.

Shier, M., Graham, J. R., \& Jones, M. E. (2009). Barriers to employment as experienced by disabled people: A qualitative analysis in Calgary and Regina, Canada. Journal of Disability \& Society, 24, 63-75. doi: 10.1080/09687590802535485

Simpson, S. N. Y. (2013). Performance contract \& performance evaluation of state owned enterprised: Insight from the goal theory. Journal of Public Administration \& Governance, 3(2), 22-39. doi: 10. 5296/jpag.v3i2.3744

Stepleton, D. C., Houtenville, A. J., Weathers, R.R., \& Burkhauser, R. V. (2009). Counting working age people with disabilities. Employment Research: Up John Institute (pp. 1-26)

Sulistyawati, A. I., \& Indrayani, R. A. (2012). Pengaruh kepuasan karyawan, training, turnover, dan produktivitas karyawan terhadap keunggulan bersaing melalui kinerja perusahaan. Jurnal Dinamika Akuntansi, 4(2), 83-93.

Welbourne, Theresa M. (2000). Effects of individual and team monitoring on employee performance: Differential outcomes under gain sharing and traditional pay. New York: Ives Hall Cornell University Ithaca.

Wibowo. (2007). Manajemen kinerja (edisi kelima). Depok, Raja Grafindo Persada

World Health Organization. (2001). International classification of functioning, disability and health. Diakses

dari https://books.google.co.id/books?hl=en\&lr=\&id=lMZPmEJrJ3sC\&oi=fnd\&pg=PA1\&dq $=$ World + Health+Organization.+(2001).+International+classification+of+functioning, + dis ability+and+health 